\title{
Irradiation Energy Effect on a Silicon Solar Cell: Maximum Power Point Determination
}

\author{
Mamadou Lamine Ba ${ }^{1}$, Hawa Ly Diallo², Hamet Yoro Ba${ }^{1}$, Youssou Traore ${ }^{2}$, Ibrahima Diatta ${ }^{2}$, \\ Marcel Sitor Diouf², Mamadou Wade1, Gregoire Sissoko² \\ ${ }^{1}$ Laboratory of Sciences and Techniques of Water and Environment, Polytechnic School of Thiès, Thiès, Senegal \\ ${ }^{2}$ Laboratory of Semiconductors and Solar Energy, Physics Department, Faculty of Science and Technology, University Cheikh \\ Anta Diop, Dakar, Senegal \\ Email: gsissoko@yahoo.com
}

How to cite this paper: Ba, M.L., Diallo, H.L., Ba, H.Y., Traore, Y., Diatta, I., Diouf, M.S., Wade, M. and Sissoko, G. (2018) Irradiation Energy Effect on a Silicon Solar Cell: Maximum Power Point Determination. Journal of Modern Physics, 9, 2141-2155. https://doi.org/10.4236/jmp.2018.912135

Received: August 29, 2018

Accepted: October 8, 2018

Published: October 11, 2018

Copyright $\odot 2018$ by authors and Scientific Research Publishing Inc. This work is licensed under the Creative Commons Attribution International License (CC BY 4.0).

http://creativecommons.org/licenses/by/4.0/

\begin{abstract}
The aim of this study is to determinate the electrical parameters of a white biased silicon solar cell submitted to an irradiation energy of particles (protons, helium, electrons and heavy ions). A theoretical study of the influence of irradiation energy on the photocurrent density, the photovoltage, the maximum power, as well as the maximum efficiency of the solar cell is presented through a resolution of the continuity equation relative to excess minority carrier. Then the expressions of the photocurrent density Jph, the photovoltage $\mathrm{Vph}$, and the excess minority carrier recombination velocity at the back side $S b$ are established dependent of irradiation parameters $\phi p, K I$ respectively irradiation flux and intensity. In this work, we propose a method for determining the recombination velocity of the excess minority carrier at the junction $S f_{\max }$ corresponding to the maximum power point delivered by the photovoltaic generator under the influence of the irradiation. It is then obtained by calculating the derivative of the power with respect to the excess minority carrier recombination velocity $S f$ at the junction emitter-base. A transcendental equation solution is deduced as eigenvalue, leading to the junction recombination velocity of excess minority carrier and also yields the solar cell maximum conversion efficiency.
\end{abstract}

\section{Keywords}

Silicon Solar Cell, Irradiation, Electrical Parameters, Maximum Power Point

\section{Introduction}

The study of the effect of radiation on solar cells designed for space applications has long occupied research fields, in order to understand the stakes in their per- 
formance opposite the high-energy radiating particles of the space environment [1] [2] [3]. These same concerns are studied at the terrestrial level in order to investigate the relationship between the solar cell parameters and those of the irradiation [4].

The aim of this study is to show the influence of irradiation energy on the electrical parameters of a silicon solar cell: photocurrent density, photovoltage, I-V characteristic, electric power and efficiency.

This work deals with a method, to determinate the maximum power point of the solar cell under the effect of the irradiation energy. Maximum Power Point Trackers (MPPT) is a well-known technique allowing the solar cell to operate at the maximum power point under varying illumination and temperature [5] [6] [7] [8] [9].

This work gives the expressions the excess minority carrier density continuity equation in the base. Then, the expressions [10] [11] of the photocurrent density, the photovoltage, the excess minority carrier excess minority carrier recombination velocity at the back side $\mathrm{Sb}$ and the electrical power, all depending on the irradiation energy are deduced. These parameters are also represented graphically as a function of the excess minority carrier recombination velocity at the junction.

The characteristic curve of the photocurrent density as a function of the photovoltage $\mathrm{I}(\mathrm{Sf})-\mathrm{V}(\mathrm{Sf})$ [12] [13] [14], is produced as irradiation parameters dependent. The power [15] [16] [17], as a function of both the recombination velocity of the excess minority carrier at the junction and the photovoltage, is also represented graphically.

A transcendental equation giving the velocity of recombination of the excess minority carrier at the points of maximum power $S f_{\max }$ is determined and the numerical values of $S f_{\max }$ are extracted graphically. We then calculated the fill factor FF of the solar cell for different values of the irradiation energy. Finally, the profiles of $S f_{\max }, V_{\max }, I_{\max }$ and $\eta_{\max }$ versus irradiation energy are shown graphically.

\section{Theory}

Consider a crystalline silicon solar cell $\left(\mathrm{n}^{+}-\mathrm{p}-\mathrm{p}^{+}\right)$[18]. Its structure is illustrated in Figure 1. Where:

$x$ is the depth in the base of the solar cell measured from the emitter-base junction, called space charge region (SCR) $(x=0)$ to the back side face $(x=H)$. $H$ is the base thickness, where a back surface field (BSF) is created by help of the $\mathrm{p}^{+}$zone.

$K l$ is the damage coefficient while $\phi p$ is the irradiation energy.

The set of different processes taking place in the base can result in the so called continuity equation:

$$
\frac{\partial^{2} \delta(x, k l, \phi p)}{\partial x^{2}}-\frac{\delta(x, k l, \phi p)}{[L(k l, \phi p)]^{2}}=-\frac{1}{D(k l, \phi p)} \cdot G(x)
$$




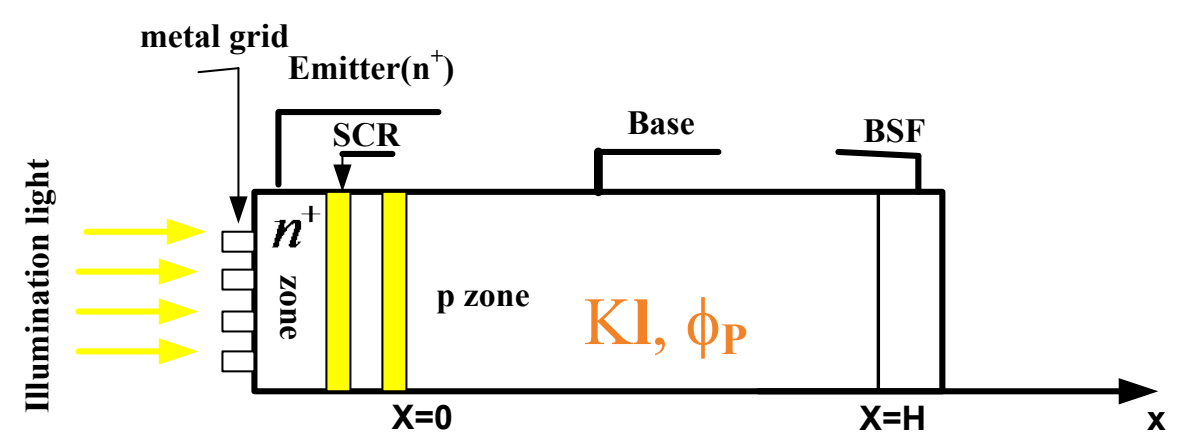

Figure 1. Structure of the silicon solar cell $\left(\mathrm{n}^{+}-\mathrm{p}-\mathrm{p}^{+}\right)$.

with:

$$
\begin{gathered}
D(k l, \phi p)=\frac{[L(k l, \phi p)]^{2}}{\tau} \\
L(k l, \phi p)=\frac{1}{\left(\frac{1}{L_{0}^{2}}+k l \cdot \phi p\right)^{1 / 2}}
\end{gathered}
$$

$D(k l, \phi p)$ is the diffusion coefficient of the electrons in the base under irradiation.

$L(k l, \phi p)$ is the diffusion length of the excess minority carriers in the base as a function of the irradiation energy flux $(\Phi p)$ and the damage coefficient intensity $(K)$. It also represents the average distance traveled by the minority carriers before their recombination in the base under irradiation.

$\delta(x, k l, \phi p)$ represents the excess minority carrier density in the base of the solar cell at the x-position, dependent of the irradiation energy.

$G(x)$ is the excess minority carrier generation rate, given by [19] [20]:

$$
G(x)=\sum_{i=1}^{3} a_{i} \mathrm{e}^{-b_{i} \cdot x}
$$

The coefficients $a_{i}$ and $b_{i}$ take into account the tabulated values of solar radiation and the dependence of the absorption coefficient of silicon with the wavelength. The resolution of the differential equation gives the expression of the excess minority carrier density in the base as:

$$
\delta(x, k l, \phi p)=A \cdot \cosh \left[\frac{x}{L(k l, \phi p)}\right]+B \cdot \sinh \left[\frac{x}{L(k l, \phi p)}\right]-\sum K_{i} \cdot \mathrm{e}^{-b_{i} \cdot x}
$$

The expressions of, $A$ and $B$ are determined from the following boundary conditions:

2-4-a: At the junction: emitter-base $(x=0)$

$$
\left.D(k l, \phi p) \frac{\partial \delta(x, k l, \phi p)}{\partial x}\right|_{x=0}=S_{f} \cdot \delta(0, k l, \phi p)
$$

2-4-b: At the back side $(x=H)$ 


$$
\left.D(k l, \phi p) \frac{\partial \delta(x, k l, \phi p)}{\partial x}\right|_{x=H}=-S_{b} \cdot \delta(H, k l, \phi p)
$$

$S_{f}$ is the excess minority carrier recombination velocity at the junction and also indicates the operating point of the solar cell [21] [22].

$S_{b}$ is the excess minority carrier recombination velocity on the back side surface [23] [24] [25]. Its expression is obtained from the derivative of the photocurrent density for large $S f$ values [21] [26] [27] that can be seen on Figure 2.

$$
\left[\frac{\partial J p h}{\partial S f}\right]=0
$$

From the relation (Equation (8)), the calculation gives the recombination velocity $S_{b}$ [10] [28] of the excess minority carrier at the back side of the solar cell, depending on parameters influenced by irradiation energy, such as, $L(k l, \varphi p)$ and $D(k l, \varphi p)$ :

$$
\begin{aligned}
& S b(k l, \phi p)=\frac{D(k l, \phi p)}{L(k l, \phi p)} \\
& \cdot \sum_{i=1}^{3} \frac{L(k l, \phi p) \cdot b_{i}\left(\mathrm{e}^{b_{i} \cdot H}-\cosh \left(\frac{H}{L(k l, \phi p)}\right)\right)-\sinh \left(\frac{H}{L(k l, \phi p)}\right)}{L(k l, \phi p) \cdot b_{i} \cdot \sinh \left(\frac{H}{L(k l, \phi p)}\right)+\cosh \left(\frac{H}{L(k l, \phi p)}\right)-\mathrm{e}^{b_{i} \cdot H}}
\end{aligned}
$$

\section{Photocurrent Density}

The expression of the photocurrent density is deduced from the excess minority carrier density in the base. It is given by the following relation:

$$
J p h(S f, k l, \phi p)=q \cdot D(k l, \phi p) \cdot\left[\frac{\partial \delta(x, k l, \phi p)}{\partial x}\right]_{x=0}
$$

Figure 2 shows the profile of the photocurrent density as a function of the excess minority carrier recombination velocity at the junction for different given values of the irradiation energy.

We note in this figure that the photocurrent density is almost zero for recombination velocity lower than $10 \mathrm{~cm} / \mathrm{s}$ (solar cell operating in open circuit). Then for $10 \mathrm{~cm} / \mathrm{s}<S f<3 \times 10^{3} \mathrm{~cm} / \mathrm{s}$, the photocurrent density increases with the recombination velocity to reach a maximum of amplitude. This shows that the excess minority carrier has acquired some energy to cross the junction.

Indeed, for recombination velocity greater than $3 \times 10^{3} \mathrm{~cm} / \mathrm{s}$, the photocurrent density is maximum and constant, corresponding to the short-circuit photocurrent.

The figure also shows that as the irradiation energy increases, the maximum amplitude of the photocurrent density decreases. This phenomenon can be explained by the interaction of the irradiating particles with the silicon material which increases and reduces the density of the excess minority carrier. 


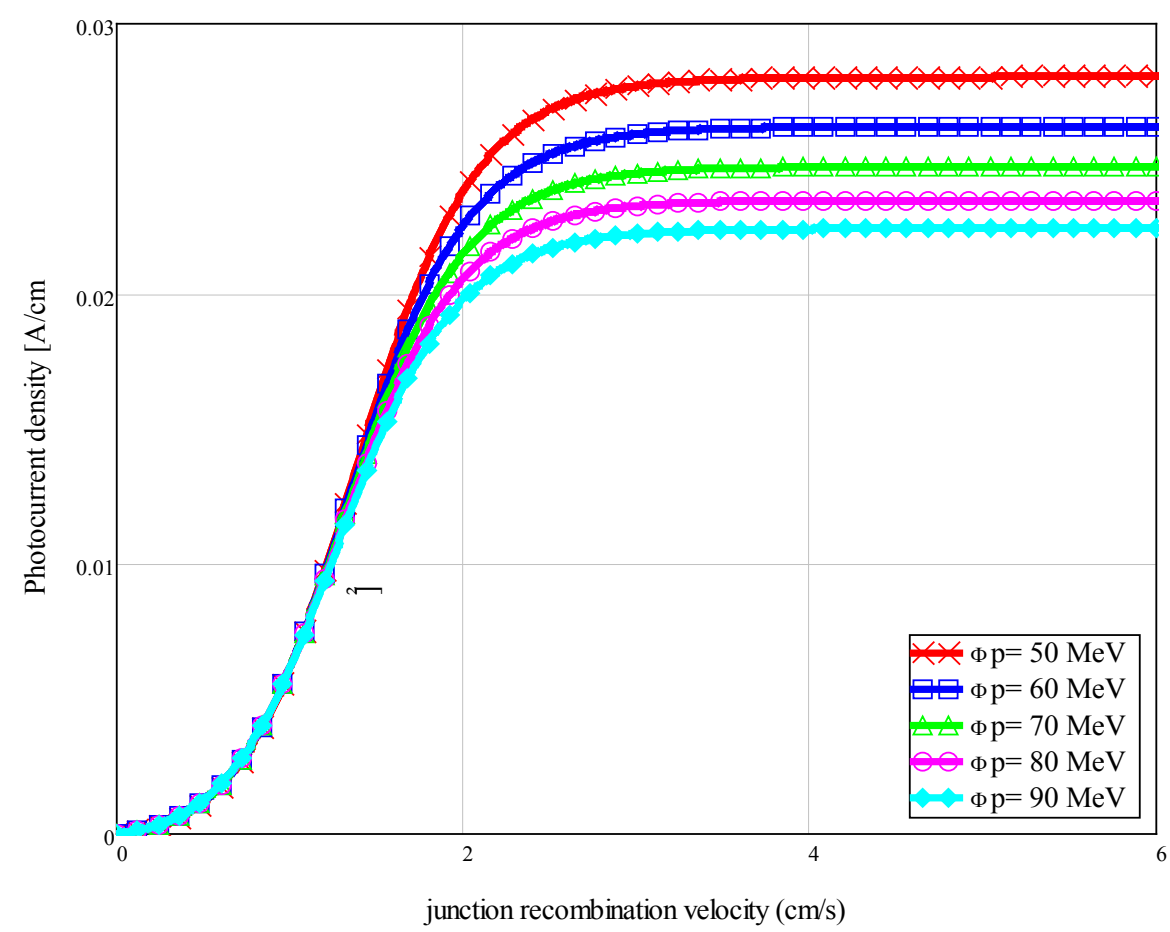

Figure 2. Photocurrent density versus junction recombination velocity for different irradiation energy values.

\section{Photovoltage}

The illuminated solar cell photovoltage expression, is obtained by the Boltzmann relation.

$$
V p h(S f, k l, \phi p)=V_{T} \cdot \ln \left(\frac{N b}{n_{i}^{2}} \cdot \delta(0, k l, \phi p)+1\right)
$$

$V_{T}$ is the thermal voltage, defined by:

$$
V_{T}=\frac{K_{b}}{q} T
$$

- $T$ is the absolute temperature $=300 \mathrm{~K}$

- $N b$ is the doping rate in acceptor atoms in the base

- $n_{i}$ is the intrinsic concentration

- $K_{b}$ is the constant of Boltzmann

- $q$ is the elementary charge of the electron

Figure 3 shows the profile of the photovoltage as a function of the excess minority recombination velocity at the junction for different values of the irradiation energy.

We note in this figure that the photovoltage is maximum and constant for recombination velocity lower than $2 \times 10^{2} \mathrm{~cm} / \mathrm{s}$; thus corresponding to solar in open circuit condition. Beyond this recombination velocity, the photovoltage linearly decreases very rapidly to reach almost zero value in the vicinity of the short-circuit and consequently, yields the crossing of almost all excess minority carrier at the junction. 


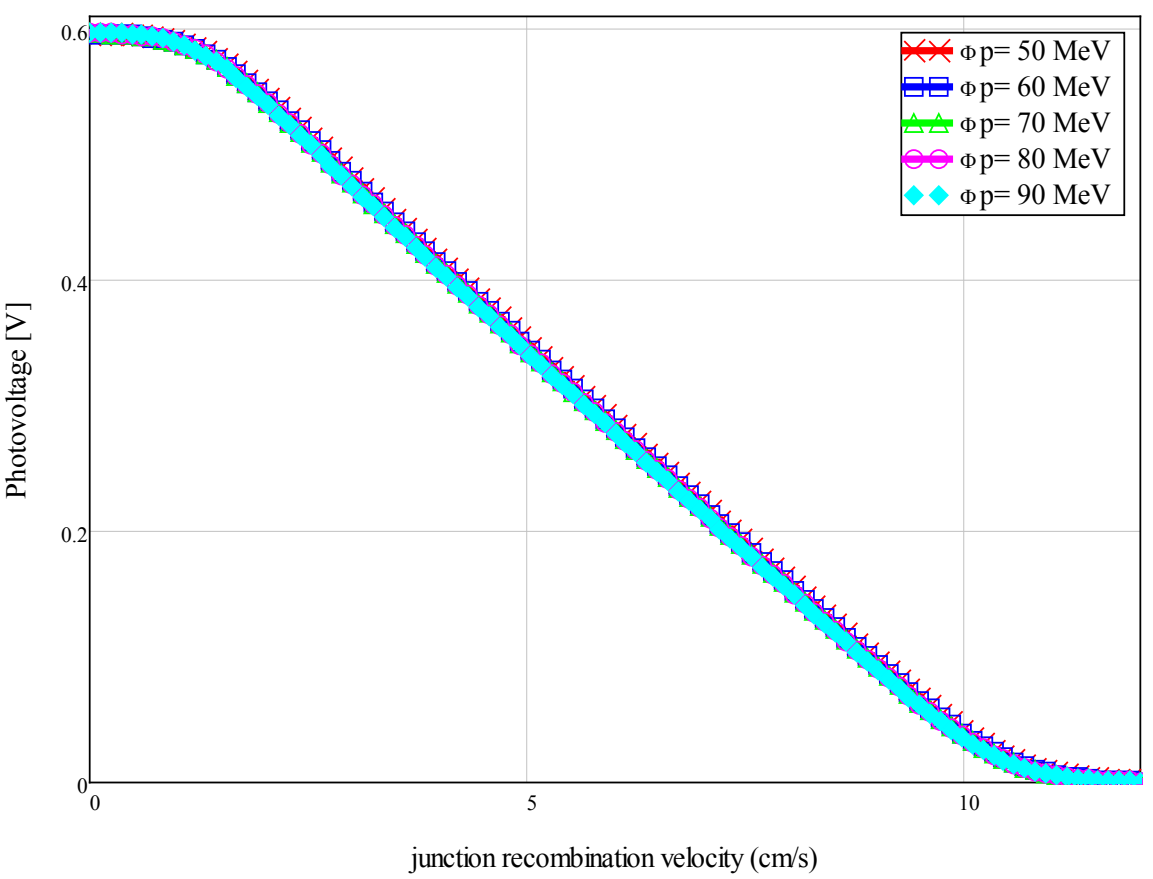

Figure 3. Photovoltage versus junction recombination velocity for different irradiation energy values.

Then, we note in this figure that the increase of the irradiation energy influences weakly the photovoltage.

\section{Illuminated Solar Cell I(Sf)-V(Sf) Characteristic Study}

The profile of the illuminated solar cell $\mathrm{I}(\mathrm{Sf})-\mathrm{V}(\mathrm{Sf})$ characteristic for different values of the irradiation energy is shown in Figure 4.

We note that the photocurrent density decreases with the increase of the irradiation energy. And the photovoltage increases slightly.

\section{Study of the Power and the Maximum Power Point}

\subsection{Electrical Power of the Solar Cell}

The equivalent electric circuit of a real solar cell under illumination is shown in Figure 5. This circuit gives the solar cell as an ideal current generator that outputs an illumination depending photocurrent density Iph, connected in parallel with a diode and a shunt resistor Rsh and in series with a series resistor Rs [29].

The ohm law applied to the circuit in Figure 5 yields the electric power delivered by the base of the solar cell to an external load as follows:

$$
P(S f, k l, \phi p)=V_{p h}(S f, k l, \phi p) \cdot I(S f, k l, \phi p)
$$

Applying the first Kirchhoff law to the circuit of Figure 5 the current delivered by an illuminated solar cell to an external load, is given by the following relationship:

$$
I(S f, k l, \phi p)=J_{p h}(S f, k l, \phi p)-I_{d}(S f, k l, \phi p)
$$




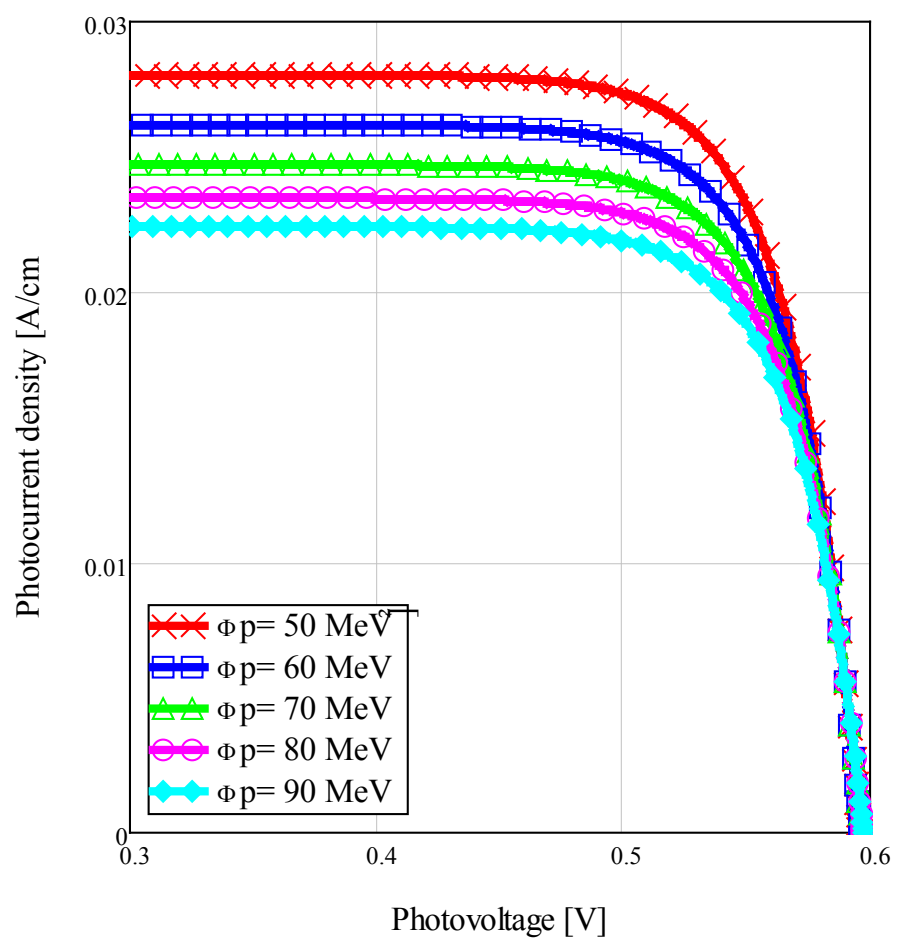

Figure 4. Photocurrent density versus photovoltage for different irradiation energy values.

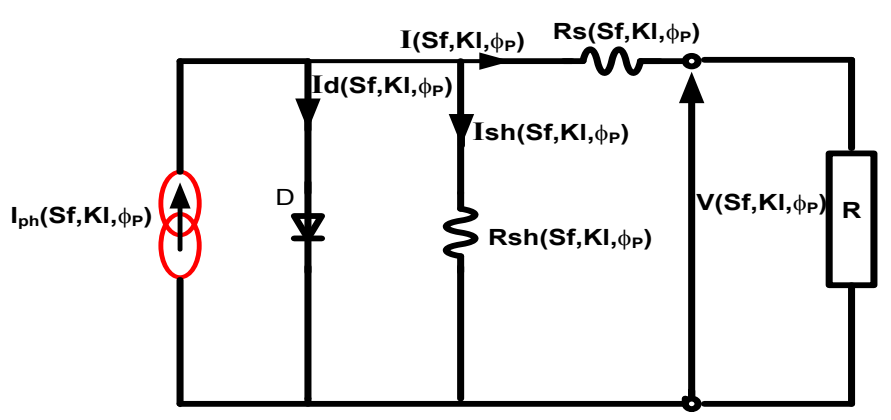

Figure 5. Equivalent electrical circuit of an illuminated solar cell.

$I_{d}$ is the diode current, its expression is given by the following relation:

$$
I_{d}(S f, k l, \phi p)=q \cdot S f_{0} \cdot \frac{n_{i}^{2}}{N b} \cdot \exp \left(\frac{V_{p h}(S f, k l, \phi p)}{V_{T}}-1\right)
$$

$S f_{0}$ is the excess minority carrier recombination velocity associated with shunt resistance-induced charge carrier losses [30] [31], which characterizes the good quality of the solar cell [21] [22] [24].

Figure 6 and Figure 7 show the variations in electrical power as a function of both, the excess minority carrier recombination velocity at the junction and the photovoltage for different values of the irradiation energy.

We note that the power grows from the high recombination velocity at the junction (Figure 6) and reaches a maximum amplitude where it decreases to tend to zero value. The maximum of this power amplitude decreases with the 


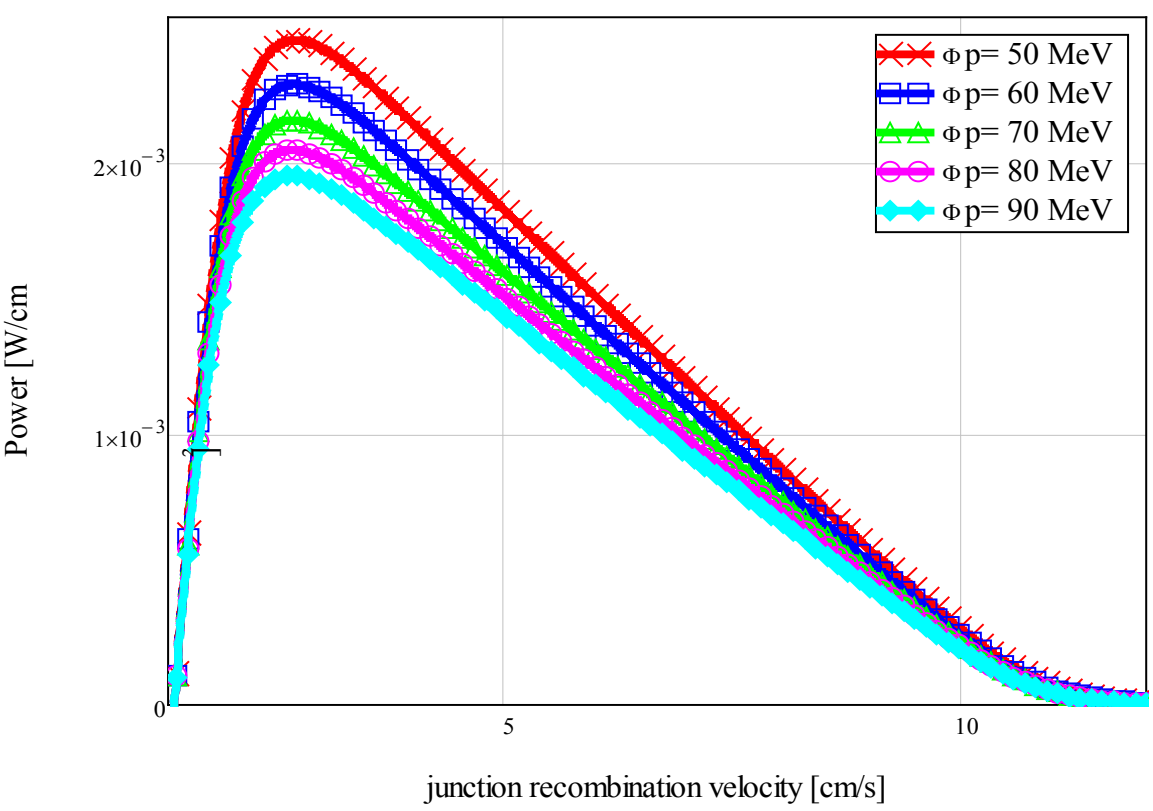

Figure 6. Solar cell power versus junction recombination velocity for different irradiation energy values.

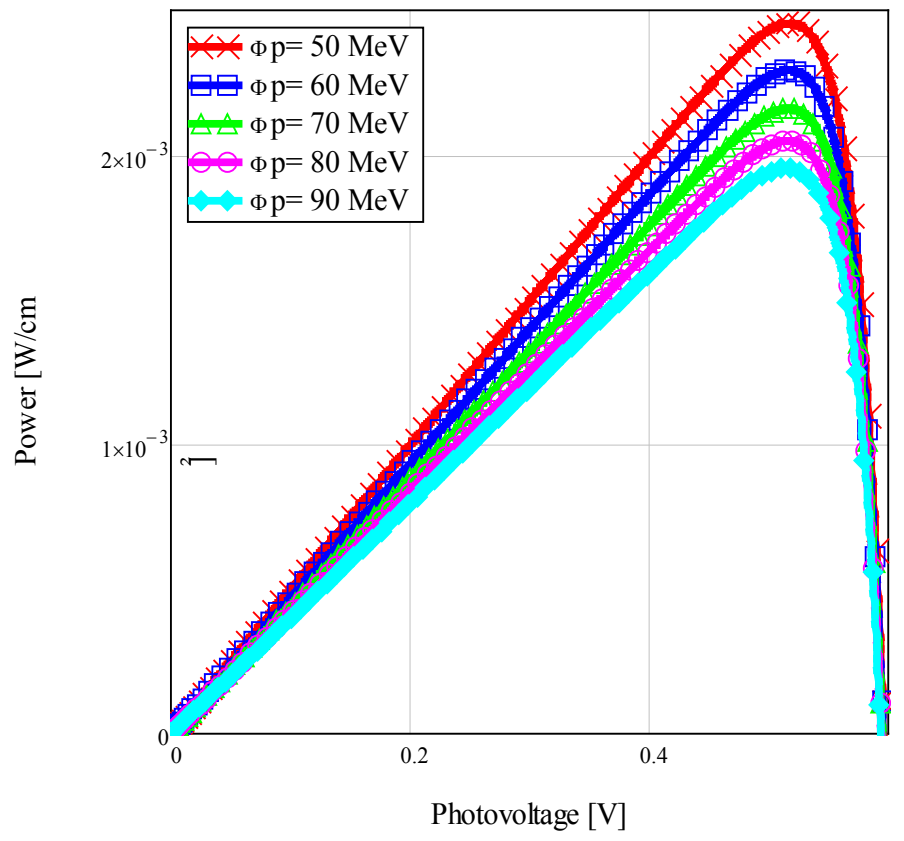

Figure 7. Solar cell power versus photovoltage for different irradiation energy values.

increase of the irradiation energy. There are three zones of variation of the power as a function of the photovoltage (Figure 7):

A short-circuit zone with a maximum photocurrent density (where the photovoltage is zero) gives a power equally zero;

$>$ A region in the vicinity of the open circuit with a maximum photovoltage (with a zero photocurrent density) provides such a zero power; 
And an intermediate zone with increasing and decreasing power passing through a maximum which is located at an intermediate operating point.

It is also observed a decrease in power with the increase of the irradiation energy.

\subsection{Maximum Power Point and Efficiency}

The maximum power point of a photovoltaic generator corresponds to the photocurrent density-photovoltage couple generating the maximum electrical power [17]. The product of the maximum photocurrent density $\mathrm{Jph}_{\max }$ and the maximum photovoltage $\mathrm{Vph}_{\max }$ gives a maximum power as $\mathrm{P}_{\max }=\mathrm{Jph}_{\max } \times \mathrm{Vph}_{\max }$.

The recombination velocity Sfmax of the excess minority carrier at the junction corresponding to the maximum power point is bring out by solving the following equation [17].

$$
\frac{\partial P}{\partial S f}=0
$$

Let $S f_{\max }$ denote the recombination velocity of the excess minority carrier at the junction corresponding to the maximum power point. It depends on both the phenomenological and geometrical parameters of the solar cell, respectively,

$L(k l, \varphi p), D(k l, \varphi p), S f(k l, \varphi p), S b(k l, \varphi p), \mu, \tau, n_{p}, N b, b_{i}$ and $H$ in the one dimensional model.

From Equation (16), the transcendental equation depending on recombination velocity $S f$ and the irradiation energy is obtained. It is given by the following expressions:

$$
M(S f, k l, \phi p)=\frac{1}{S f_{\max } L(k l, \phi p)} \cdot\left[1-\frac{S f_{\max } L(k l, \phi p)}{Y_{1} \cdot D(k l, \phi p)+S f_{\max } L(k l, \phi p)}\right]
$$

And:

$$
\begin{aligned}
N(S f, k l, \phi p)= & {\left[\frac{\Gamma_{\text {max }}(0, k l, \phi p)}{\left(\Gamma_{\max }(0, k l, \phi p)+\frac{n_{i}^{2}}{N b}\right) \cdot\left(S f_{\max } \cdot L(k l, \phi p)+Y_{1} \cdot D(k l, \phi p)\right)}\right] } \\
& \times\left[\frac{1}{\log \left(\frac{N b \cdot \Gamma_{\max }(0, k l, \phi p)}{n_{i}^{2}}+1\right)}\right]
\end{aligned}
$$

$\Gamma_{\max }(0, k l, \phi p)$ is the density of the minority excess minority carrier at the point of maximum power, its expression is given by the following relation:

$$
\Gamma_{\max }(0, k l, \phi p)=\beta \cdot D(k l, \phi p) \cdot\left[\frac{Y_{2}+Y_{1}-b_{i} \cdot L(k l, \phi p)}{S f_{\max } \cdot L(k l, \phi p)+Y_{1} \cdot D(k l, \phi p)}\right]
$$

with: 


$$
\begin{gathered}
\beta=\frac{n \cdot a_{i} \cdot L(k l, \phi p)^{2}}{D(k l, \phi p) \cdot\left(L(k l, \phi p)^{2} \cdot b_{i}^{2}-1\right)} \\
Y_{1}=\frac{\frac{D(k l, \phi p)}{L(k l, \phi p)} \cdot \sinh \left(\frac{H}{L(k l, \phi p)}\right)+S b(k l, \phi p) \cdot \cosh \left(\frac{H}{L(k l, \phi p)}\right)}{\frac{D(k l, \phi p)}{L(k l, \phi p)} \cdot \cosh \left(\frac{H}{L(k l, \phi p)}\right)+S b(k l, \phi p) \cdot \sinh \left(\frac{H}{L(k l, \phi p)}\right)} \\
Y_{2}=\frac{\left(D(k l, \phi p) \cdot b_{i}-S b(k l, \phi p)\right) \cdot \exp \left(-b_{i} \cdot H\right)}{\frac{D(k l, \phi p)}{L(k l, \phi p)} \cdot \cosh \left(\frac{H}{L(k l, \phi p)}\right)+S b(k l, \phi p) \cdot \sinh \left(\frac{H}{L(k l, \phi p)}\right)}
\end{gathered}
$$

The graphical resolution of this transcendental equation as a function of the excess minority carrier recombination velocity $S f$ at the junction, for different values of the irradiation energy, gives the $S f_{\max }$ values by the intercept point of the two curves represented by Figure 8. At each $S f_{\max }$ operating point, the electrical power delivered by the photovoltaic generator, is maximum.

Figure 8 shows a decrease in the $S f_{\max }$ values as the irradiation energy increases. This reflects the decrease in maximum power as the irradiation energy increases. We observe the intercept points in the figure, corresponding to the values of $S f_{\max }$. These values of $S f_{\max }$ correspond to a condition of solar cell operating at its maximum power point.

The results obtained from Figure 8 corresponding to the numerical values of $S f_{\max }$ for each maximum power point, are given in Table 1.

The influence of the irradiation energy on the $S f_{\max }$ is represented by Figure 9 .

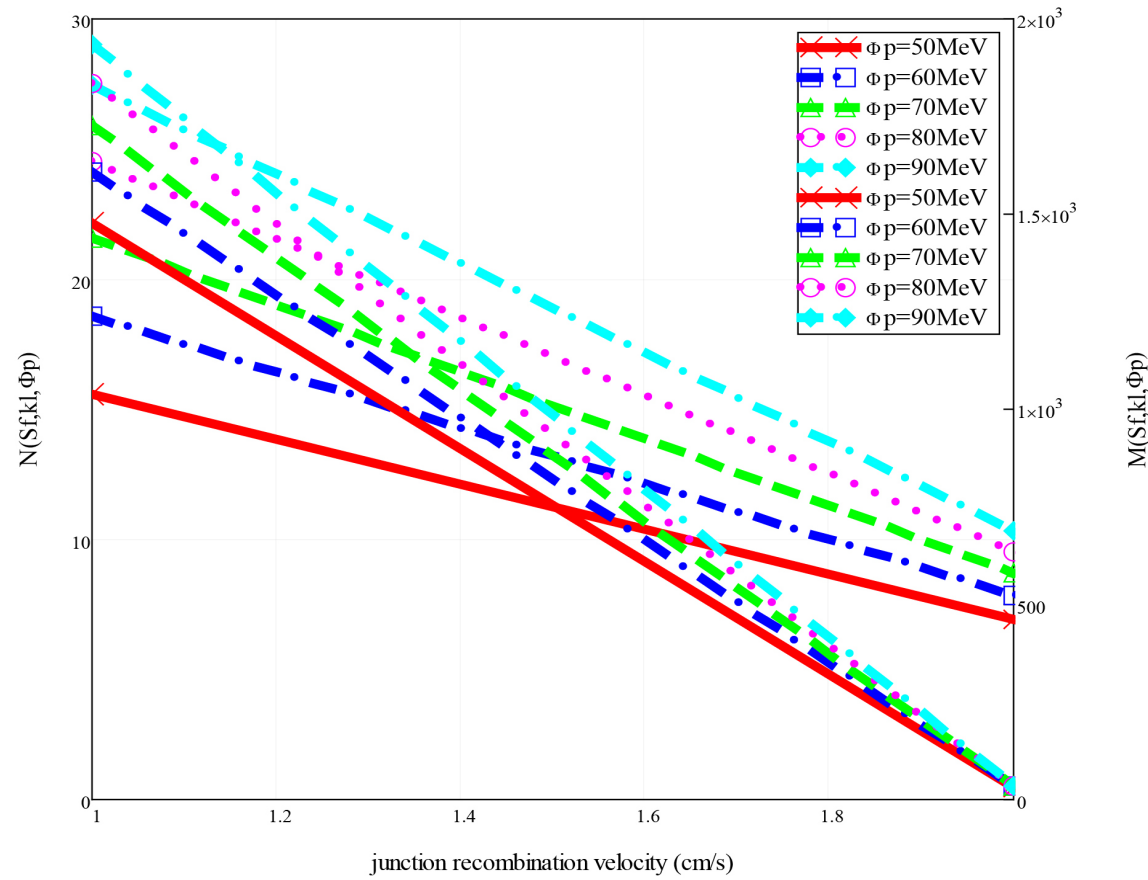

Figure 8. Representation of transcendental equation versus junction recombination velocity for different irradiation energy values. 


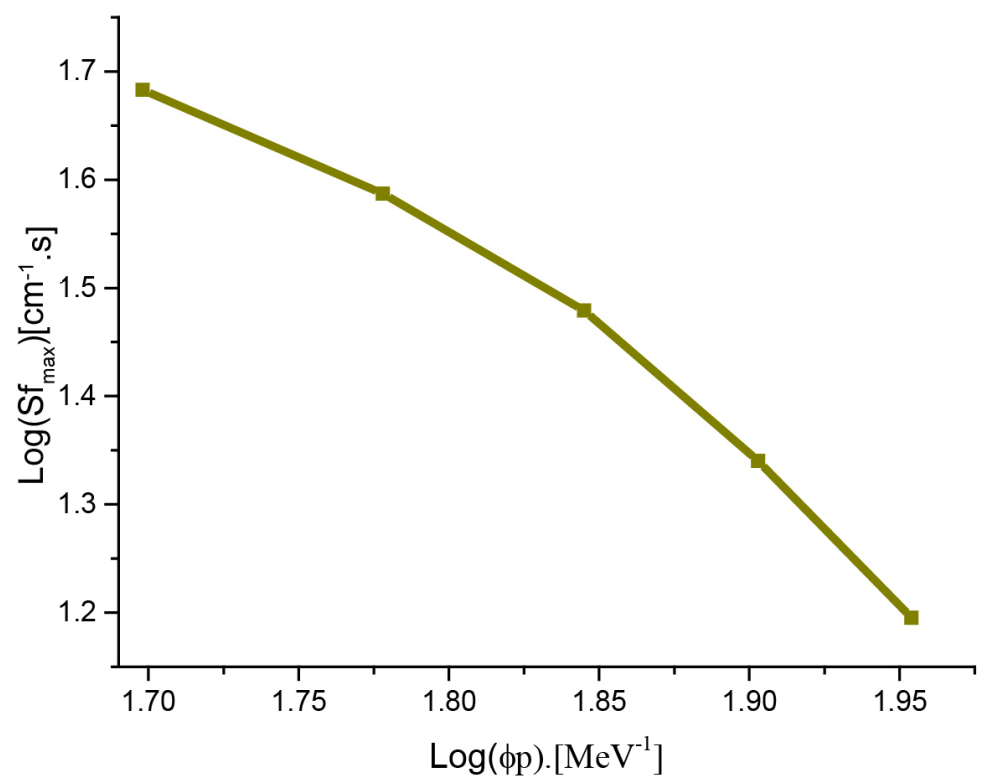

Figure 9. $S f_{\max }$ versus irradiation energy.

Table 1. The numerical values of $S f_{\max }$ corresponding to the maximal power point for different irradiation energy values.

\begin{tabular}{ccc}
\hline Irradiation energy $(\mathrm{MeV})$ & $\begin{array}{c}\text { Intercept points for given irradiation } \\
\text { energy values }(\mathrm{p})\end{array}$ & $\boldsymbol{S f}_{\max }\left(\mathrm{p} \cdot 10^{\mathrm{p}} \mathrm{cm} / \mathrm{s}\right)$ \\
\hline $\mathbf{5 0}$ & 1.506 & 47.624 \\
$\mathbf{6 0}$ & 1.432 & 35.970 \\
$\mathbf{7 0}$ & 1.349 & 26.924 \\
$\mathbf{8 0}$ & 1.251 & 24.967 \\
$\mathbf{9 0}$ & 1.139 & 15.728 \\
\hline
\end{tabular}

The recombination velocity $S f_{\max }$ of the excess minority carrier at the junction decreases with the irradiation energy.

\section{The Efficiency}

The conversion efficiency of a solar cell is the ratio between the maximum power supplied provided by the solar cell and the incident light power absorbed. It is written as follows:

$$
\eta=\frac{I_{\max } \cdot V_{\max }}{P_{\text {incident }}}
$$

$P_{\text {incident }}$ is the incident light power absorbed by the solar cell, with $P_{\text {incident }}=100 \mathrm{~mW} / \mathrm{cm}^{2}$ in the standard conditions Air Mass 1.5 .

The representation of the efficiency is deduced from the I-V characteristic curve (Figure 4). The graphical values corresponding to the maximum power point, leading to both, the maximum photocurrent and the maximum photovoltage, allowed to obtain the photovoltaic efficiency conversion for different values of the irradiation energy. These results are noted in Table 2. 
Table 2. Table of parameters leading to the efficiency $\eta_{\max }$ corresponding to the maximal power point for different irradiation energy values.

\begin{tabular}{cccccc}
\hline $\begin{array}{c}\text { Irradiation } \\
\text { energy }(\mathrm{MeV})\end{array}$ & 50 & 60 & 70 & 80 & 90 \\
\hline$I_{\max }\left(\mathrm{A} / \mathrm{cm}^{2}\right)$ & 0.02802 & 0.02619 & 0.02470 & 0.02346 & 0.02241 \\
$I_{d}\left(S f_{\max }\right)(\mathrm{A})$ & $0.19578 \times 10^{-3}$ & $0.19616 \times 10^{-3}$ & $0.19655 \times 10^{-3}$ & $0.19692 \times 10^{-3}$ & $0.19729 \times 10^{-3}$ \\
$V_{\max }(\mathrm{V})$ & 0.59549 & 0.59606 & 0.59652 & 0.59692 & 0.59726 \\
$\boldsymbol{P}_{\max }\left(\mathrm{W} / \mathrm{cm}^{2}\right)$ & 0.016569 & 0.015494 & 0.014617 & 0.013886 & 0.013267 \\
$\mathrm{FF}$ & 0.016682 & 0.015605 & 0.014731 & 0.014003 & 0.013381 \\
$\eta_{\max }(\%)$ & 16,569 & 15.494 & 14.617 & 13.886 & 13.267 \\
\hline
\end{tabular}

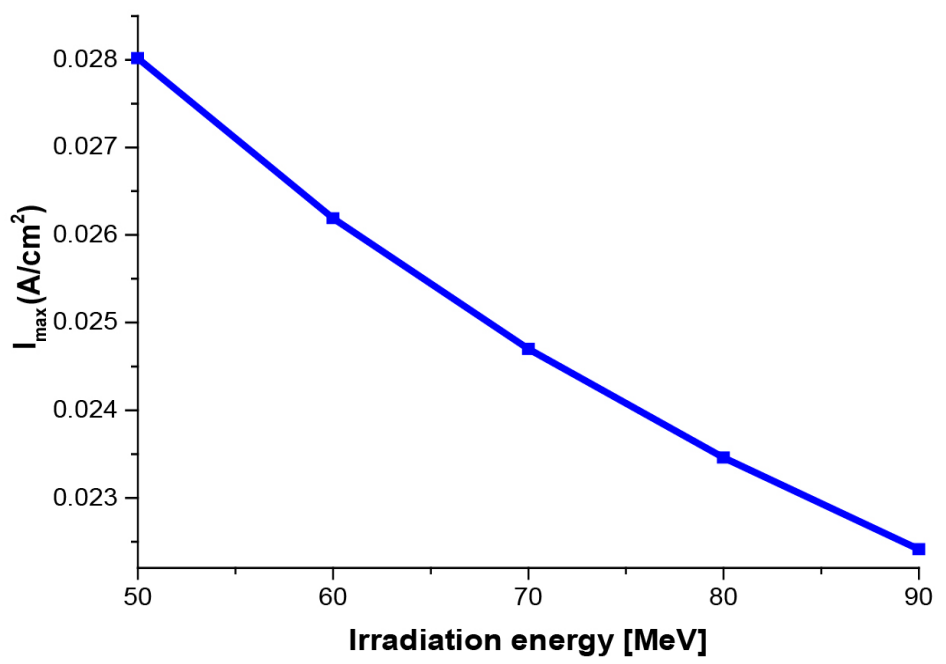

Figure 10. Maximal photocurrent versus irradiation energy.

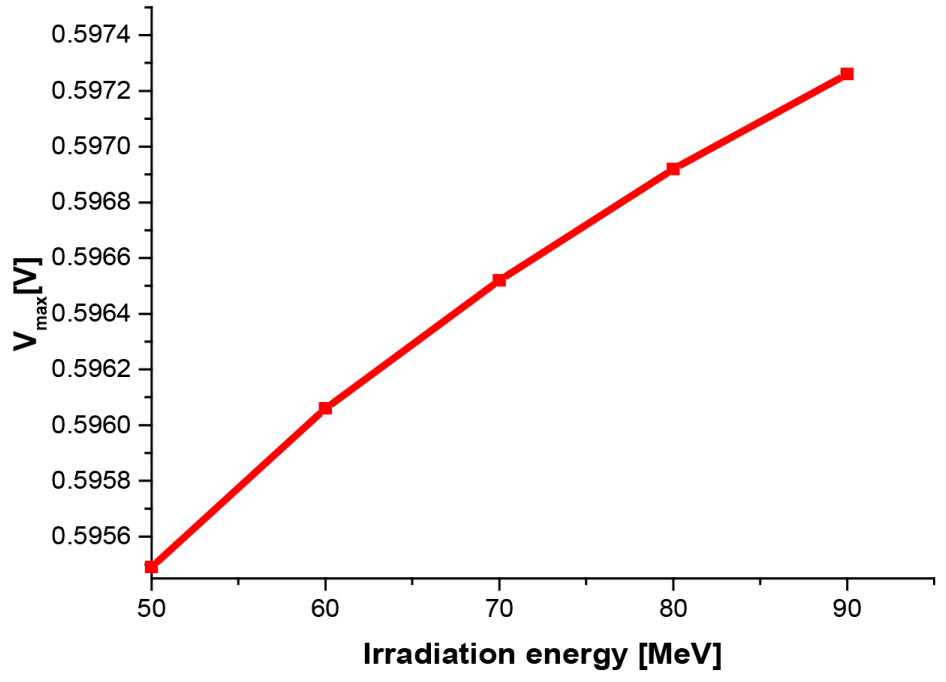

Figure 11. Maximal photovoltage versus irradiation energy.

Figures 10-12 show the maximum photocurrent $I_{\max }$, the maximum photovoltage $V_{\max }$ and the maximum conversion efficiency $\eta_{\max }$ of the solar cell as a function of the irradiation energy. 


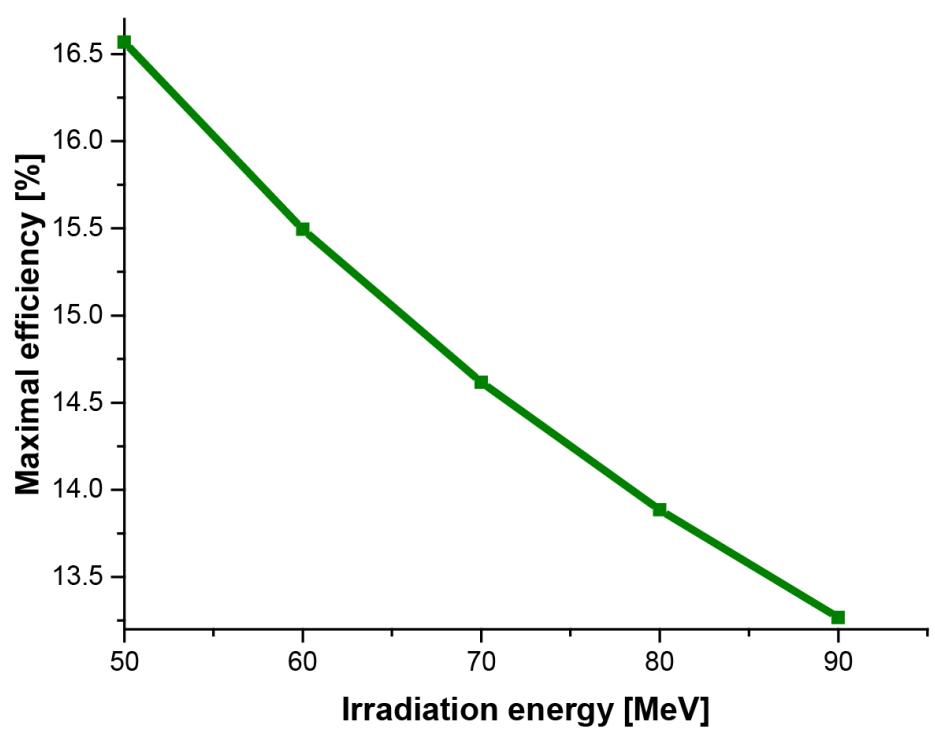

Figure 12. Maximal conversion efficiency versus irradiation energy.

These results show that, the recombination velocity of the excess minority carrier $S f_{\max }$ at the junction yielding, the maximum photocurrent as well as the photovoltaic conversion efficiency, decrease when the irradiation energy increases, contrary to the maximum photovoltage which increases with the energy of irradiation. This results in a variation of the peak power point as the irradiation energy increases.

\section{Conclusions}

In this work, from the expression of the excess minority carrier density in the base, the photocurrent density and the photovoltage, lead to the illuminated I-V characteristic of the solar cell under irradiation. This study showed us a decrease in short-circuit photocurrent and an increase in open-circuit photovoltage as irradiation energy increases. The decrease of the short-circuit photocurrent is manifested by a decrease in the excess minority carrier density that crosses the junction as the irradiation energy increases.

From the dark and illuminated I-V characteristics, we have studied the electric power delivered by the base of the solar cell as a function of the excess minority carrier recombination velocity $S f$ at the junction. The power increases with the recombination velocity $S f$ as well as the photovoltage up to a maximum value which represents the maximum power point. Then it decreases to cancel at a value corresponding to the open circuit voltage (very low $S f$ ).

A transcendental equation graphically resolved, gives eigenvalue, represented by the recombination velocity of the excess minority carrier $S f_{\max }$ corresponding to the maximum power point of the solar cell under different values of the irradiation energy.

Finally we calculated and plotted solar cell electrical parameters $I_{\max }, V_{\max }$ and $\eta_{\max }$ versus the applied irradiation energy. 


\section{Conflicts of Interest}

The authors declare no conflicts of interest regarding the publication of this paper.

\section{References}

[1] Martin, J.E. (2006) Physics for Radiation Protection: A Handbook. 2nd Edition, Wiley-VCH, Weinheim. https://doi.org/10.1002/9783527618798

[2] Fatemi, N.S., Sharps, P.R., Stan, M.A., Aiken, D.J., Clevenger, B. and Hou, H.Q. (2001) Radiation-Hard High-Efficiency Multi-Junction Solar Cells for Commercial Space Applications. Proceedings of the $17^{\text {th }}$ European Photovoltaic Solar Energy Conference, 2155-2158.

[3] Kreinin, L., Bordin, N. and Eisenberg, N. (2007) Spectral Response of Light Biased Si Solar Cells at Open Circuit Voltage. Proceedings of the 14th Sede Boqer Symposium on Solar Electricity Production, 19-21 February 2007, 71-76.

[4] Ohshima, T., Sumita, T., Imaizumi, M., Kawakita, S., Shimazaki, K., Kuwajima, S., Ohi, A. and Itoh, H. (2005) Evaluation of the Electrical Characteristics of III-V Compounds Solar Cells Irradiated with Protons at Low Temperatures. Proceedings of the $31^{\text {st }}$ IEEE Photovoltaic Specialists Conference, Lake Buena Vista, FL, 3-7 January 2005,806

[5] Ould El Moujtaba, M.A., Ndiaye, M., Diao, A., Thiame, M., Barro, I.F. and Sissoko, G. (2012) Research Journal of Applied Sciences, Engineering and Technology, 4 , 5068-5073.

[6] Gaye, I., Sam, R., Seré, A.D., Barro, I.F., Ould El Moujtaba, M.A., Mané, R. and Sissoko, G. (2012) International Journal of Emerging Trends \& Technology in Computer Science (IJETTCS), 1, 210-214,

[7] Sow, O., Diarisso, D., Zénobe, N., MBodji, A., Diallo, M.S., Diao, A., Gaye, I., Barro, F.I. and Sissoko, G. (2013) International Journal of Innovative Technology and EXploring Engineering (IJITEE), 2, 330-334.

[8] Dione, B., Sow, O., Wade, M., Ibrahima, L.Y., Mbodji, S. and Sissoko, G. (2016) Circuits and Systems, 7, 3984-4000. https://doi.org/10.4236/cs.2016.711330

[9] Barro, F.I., Seidou Maiga, A., Wereme, A. and Sissoko, G. (2010) Physical and Chemical News, 56, 76-84.

[10] Diallo, M.M., Tamba, S., Seibou, B., Cheikh, M.L.O., Diatta, I., El Hadji Ndiaye, Traore, Y., Sarr, C.T. and Sissoko, G. (2017) Journal of Scientific and Engineering Research, 4, 29-40.

[11] Gaye, I., Ould El Moujtaba, M.A., Thiam, N., Tall, I. and Sissoko, G. (2014) Current Trends in Technology and Science, 3, 98-104.

[12] Dieye, M., Mbodji, S., Zoungrana, M., Zerbo, I., Dieng, B. and Sissoko, G. (2015) World Journal of Condensed Matter Physics, 5, 275-283. https://doi.org/10.4236/wjcmp.2015.54028

[13] Ly, I., Wade, M., Ly Diallo, H., El Moujtaba, M.A.O., Lemtabott, O.H., Mbodji, S., Diasse, O., Ndiaye, A., Gaye, I., Barro, F.I., Wereme, A. and Sissoko, G. (2011) Irradiation Effect on the Electrical Parameters of a Bifacial Silicon Solar Cell under Multispectral Illumination. Proceedings of 26 th European Photovoltaic Solar Energy Conference and Exhibition, 785-788.

[14] Sow, O., Zerbo, I., Mbodji, S., Ngom, M.I., Diouf, M.S. and Sissoko, G. (2012) International Journal of Sciences and Technology, 1, 230-246. 
[15] Sissoko, G., Correa, A., Nanema, E., Diarra, M.N., Ndiaye, A.L. and Adj, M. (1998) Recombination Parameters Measurement in Silicon Double Sided Surface Field Cell. Proceeding of the World Renewable Energy Congress, Florence, 20-25 September 1998, 1856-1859.

[16] Madougou, S., Made, F., Boukary, M.S. and Sissoko, G. (2007) Advanced Materials Research, 18-19, 303-312.

[17] Sylla, B.D.D., Ly, I., Sow, O., Dione, B., Traore, Y. and Sissoko, G. (2018) Journal of Modern Physics, 9, 172-188. https://doi.org/10.4236/jmp.2018.92011

[18] Nam, L., Rodot, M., Nijs, J., Ghannam, M. and Coppye, J. (1992) Journal de Physique III, EDP Sciences, 2, 1305-1316.

[19] Furlan, J. and Amon, S. (1985) Solid State Electronics, 28, 1241-1243. https://doi.org/10.1016/0038-1101(85)90048-6

[20] Mohammad, S.N. (1987) Journal of Applied Physics, 28, 767-772. https://doi.org/10.1063/1.338230

[21] Sissoko, G., Sivoththanam, S., Rodot, M. and Mialhe, P. (1992) Constant Illumination-Induced Open Circuit Voltage Decay (CIOCVD) Method, as Applied to High Efficiency Si Solar Cells for Bulk and Back Surface Characterization. 11 th European Photovoltaic Solar Energy Conference and Exhibition, Montreux, 352-354.

[22] Diallo, H.L., Seïdou Maiga, A., Wereme, A. and Sissoko, G. (2008) The European Physical Journal Applied Physics, 42, 203-211. https://doi.org/10.1051/epjap:2008085

[23] Rose, B.H. and Weaver, H.T. (1983) Journal of Applied Physics, 54, 238-247. https://doi.org/10.1063/1.331693

[24] Joardar, K., Dondero, R.C. and Schroder, D.K. (1989) Solid-State Electronics, 32, 479-483. https://doi.org/10.1016/0038-1101(89)90030-0

[25] Sissoko, G., Museruka, C., Corréa, A., Gaye, I. and Ndiaye, A.L. (1996) Renewable Energy, 3, 1487-1490.

[26] Bocande, Y.L., Corréa, A., Gaye, I., Sow, M.L. and Sissoko, G. (1994) Proceedings of the World Renewable Energy Congress, 3, 1698-1700.

[27] Sissoko, G., Nanéma, E., Corréa, A., Biteye, P.M., Adj, M. and Ndiaye, A.L. (1998) Renewable Energy, 3, 1848-1851.

[28] Diallo, M.M., Seibou, B., Ba, H.Y., Zerbo, I. and Sissoko, G. (2014) Current Trends in Technology and Sciences, 3, 416-421.

[29] Mbodji, S., Ly, I., Diallo, H.L., Dione, M.M., Diasse, O. and Sissoko, G. (2012) Research Journal of Applied Sciences, Engineering and Technology, 4, 1-7.

[30] Thiam, N., Diao, A., Ndiaye, M., Dieng, A., Thiam, A., Sarr, M., Maiga, A.S. and Sissoko, G. (2012) Research Journal of Applied Sciences, Engineering and Technology, 4, 4646-4655.

[31] Ly Diallo, H., Wade, M., Ly, I., Ndiaye, M., Dieng, B., Lemrabott, O.H., Maïga, A.S. and Sissoko, G. (2002) Research Journal of Applied Sciences, Engineering and Technology, 4, 1672-1676. 